\title{
Systemic response to local urate crystal induced inflammation in man: a possible model to study the acute phase response
}

\author{
C W HUTtON, ${ }^{2}$ A J COLLINS, ${ }^{1}$ R E CHAMBERS, ${ }^{3} \mathrm{~J}$ WHICHER, ${ }^{3}$ AND \\ $P$ A DIEPPE
}

From the 'School of Pharmacy and Pharmacology, University of Bath; the ${ }^{2}$ Department of Medicine, Bristol Royal Infirmary; and the ${ }^{3}$ Department of Chemical Pathology, Bristol Royal Infirmary

SUMMARY The production of a systemic inflammatory response to intradermal monosodium urate crystal injection is described. A transient, self-limiting local response is associated with a systemic response detectable by a rise in the white cell count and serum amyloid A protein. The white cell change parallels the evolution of the local response, whereas the serum amyloid A response lags behind the local lesion, peaking after the local lesion is resolving. Intradermal monosodium urate injection is proposed as a possible inflammatory stimulus to explore the acute phase protein response in different disease states.

The systemic response to inflammation includes fever, the synthesis and release of acute phase proteins, including $\mathrm{C}$-reactive protein (CRP) and serum amyloid A protein (SAA), by the hepatocyte, leucocytosis, and muscle protein catabolism. It is a feature of many conditions associated with severe inflammation and tissue damage. These include the monosodium urate induced crystal synovitis of acute gout, where leucocytosis, a raised erythrocyte sedimentation rate (ESR), and fever have long been recognised. However, the mechanisms involved in the response remain unclear. Present evidence suggests that cytokines, in particular interleukin 1, are produced by cells, including macrophages, at the site of the lesion and act as important mediators. This may be a common pathway in the many conditions in which the systemic response is observed. ${ }^{2}$ Similarly, the significance of the components of the response, for example the role of $\mathrm{C}$-reactive protein and serum amyloid $\mathrm{A}$ protein in many conditions, including gout, remains elusive.

Even more intriguing is the possibility that abnormalities in the response may occur in some diseases and that these may indeed also be important in their pathogenesis. In systemic lupus erythematosus there

Accepted for publication 12 February 1985.

Correspondence to Dr C W Hutton. Department of Medicine. Bristol Royal Infirmary. Bristol BS2 8HW. is a possibility that the acute phase response is blunted during flares of the disease activity, ${ }^{3}$ and in scleroderma there is a diminished fever and acute phase response after prostaglandin infusions. ${ }^{4}$ However, because of the variability of natural stimuli, it is impossible to make accurate comparisons between different diseases. A standard stimulus acceptable to patients and volunteers is required. This would therefore be dependent on the identification of a mild transient local inflammatory lesion that is able to trigger an inflammatory response. Etiocholanolone has been shown by McAdam to stimulate an acute phase response ${ }^{5}$ when injected intramuscularly, but the uncertainty about toxicity limits its widespread use in man. Monosodium urate (MSU) would appear to satisfy many features of a suitable agent. It occurs naturally in man but when crystalline is associated with the inflammation in gout. It is readily synthesised, and the artificial crystal appears to be clinically, physically, and biologically identical with naturally occurring crystals. In normouricaemic people the crystal is metastable and will dissolve rapidly and be cleared by existing pathways. Freudweiler ${ }^{\mathrm{b}}$ showed that synthetic monosodium urate injected into the skin produces a local inflammatory lesion, and others ${ }^{7-9}$ have shown that intra-articular injection produces acute synovitis identical with an acute attack of 
gout. However, none of these investigators explored the possibility of an associated systemic inflammatory response. We therefore determined to explore the possibility that intradermal monosodium urate might produce a systemic inflammatory response in association with a local lesion sufficiently mild and transient to be suitable for a wider study of the inflammatory response in man.

\section{Patients and methods}

Eighteen volunteers, six men and 12 women, aged between 25 and 40, were recruited after Ethical Committee approval of the project had been obtained.

Monosodium urate crystals were prepared by the method of Seegmiller ${ }^{7}$ in sterile conditions, and heated to $180^{\circ} \mathrm{C}$ for three hours to ensure no risk of endotoxin contamination. All experiments were performed using the same batch of crystals. $10 \mathrm{mg}$ crystals suspended by sonication in $0.2 \mathrm{ml}$ of sterile saline was injected intradermally in alcohol-cleaned dry skin on the non-dominant forearm of each subject. The local response was monitored by measuring the mean diameter of the lesion, that is the mean of the maximum diameter and the maximal diameter perpendicular to this diameter's axis. All measurements were made by a single observer. Any systemic response was investigated by sampling venous blood from the dominant arm to

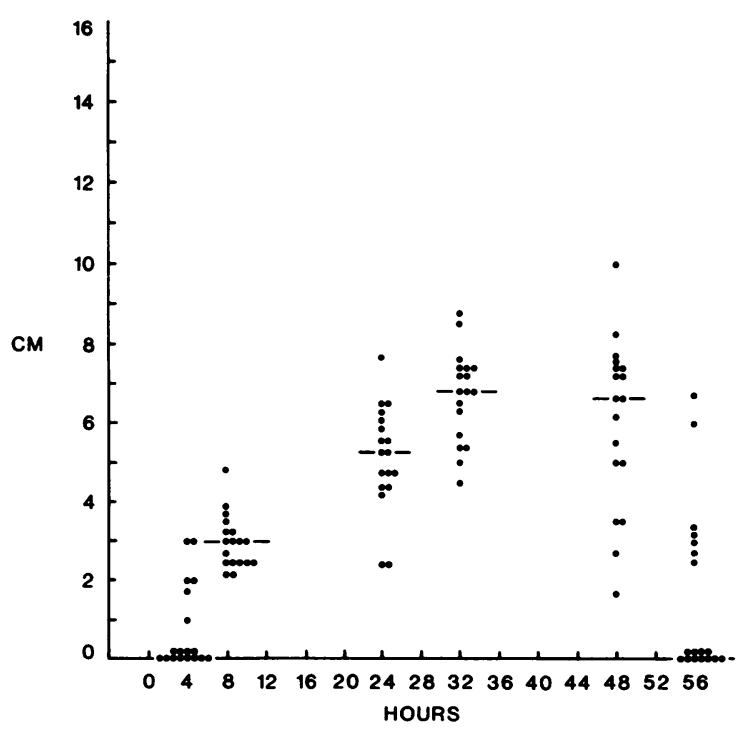

Fig. 1 Mean diameter of local lesion.

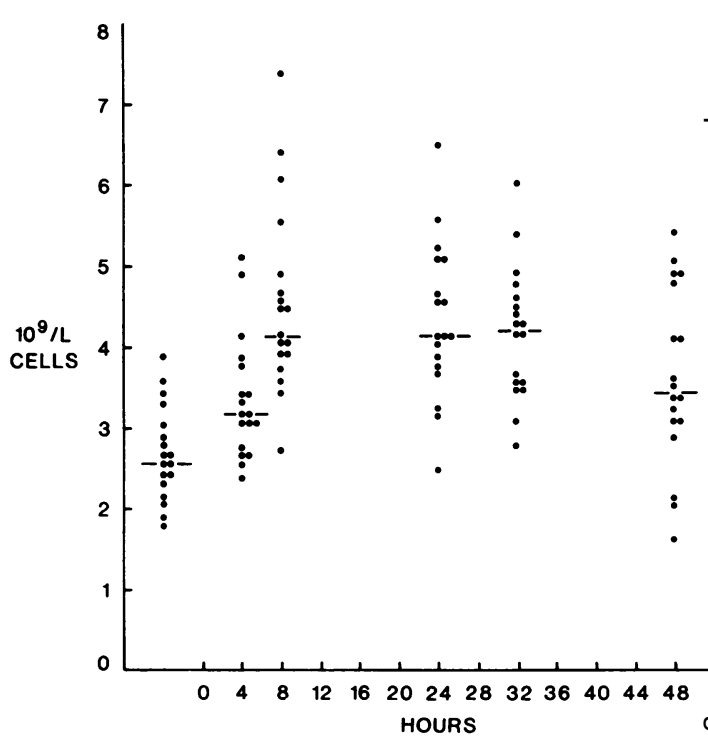

Fig. 2 Polymorphonuclear leucocyte response.

measure changes in white blood cell count, viscosity, SAA, and CRP. SAA protein was measured byo radial immunodiffusion, with antibody from Atlan-0 tic Antibodies, Westbrook, Maine, USA, by the method described by Chambers and Whicher. ${ }^{10}$ The $\overrightarrow{\overrightarrow{0}}$ lower limit of sensitivity is $0.002 \mathrm{~g} / 1$ with a normal range of less than $0.03 \mathrm{~g} / \mathrm{l}$. CRP was measured by radial immunodiffusion, with antibodies from? Seward Laboratories, London, with a lower limit of sensitivity of $0.005 \mathrm{~g} / \mathrm{l}$, normal range less than 0.010 g/l. Measurements were taken at 0,4 , and 8 hours to define the onset of the lesion, and at 24,32 , and 48 . hours to assess the magnitude of the response. The results were assessed for significant change from baseline values by Wilcoxon's signed ranks test.

\section{Results}

The intradermal monosodium urate crystals prot duced a transient erythematous non-irritant papule that was not painful but was tender on pressure This developed eight hours after injection and peaked between 24 and 32 hours (Fig. 1); it therf rapidly resolved.

Associated with this mild local lesion was evi dence of a marked systemic response. There was क rise in the white cell count by four hours that was predominantly polymorphonuclear neutrophil and if peaked at eight hours, declining gradually over $48^{\circ}$ hours (Fig. 2). There was also a rise in lymphocytes? 


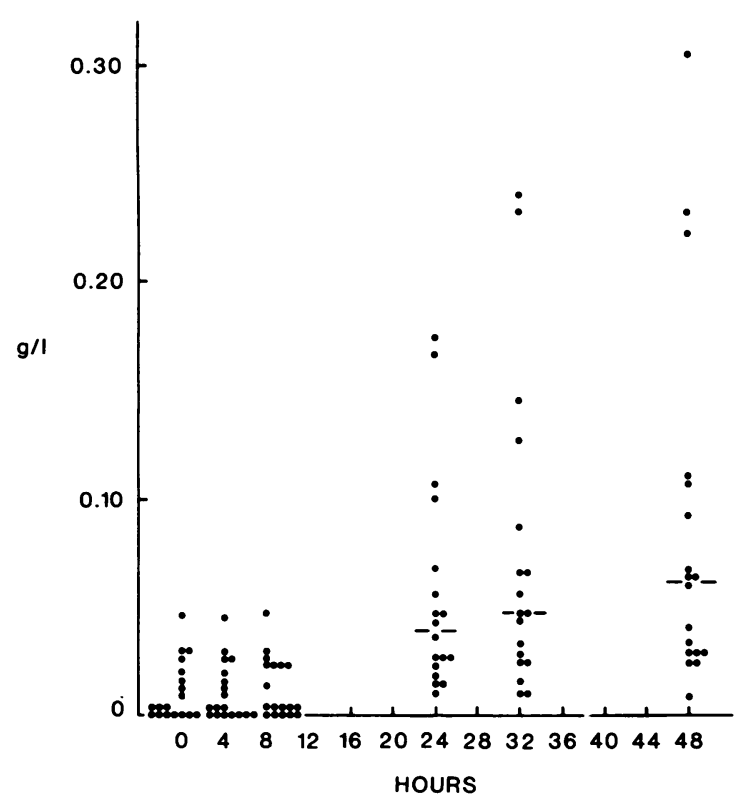

Fig. 3 Serum amyloid $A$ prötein response.

though this only reached significance at eight hours $(p=0.01)$. There was no change in haemoglobin, packed cell volume, red cell count, eosinophil count, or plasma viscosity. An acute phase response was detected by a rise in serum amyloid $A$ proteins (Fig. 3). This developed at 24. hours $(p=0 \cdot 01)$ and continued beyond the period of the study. In .eight subjects an increase was detected in the C-reactive protein level after 24 hours.

\section{Discussion}

The production of local dermal inflammation in response to crystalline MSU was first described by Freudweiler. ${ }^{6}$ Ambanelli ${ }^{11}$ who investigated the possibility that non-steroidal anti-inflammatory drugs would influence the lesion, and Dieppe,${ }^{12}$ who explored the possibility of a difference in the response in various associated diseases, also described a similar transient local lesion as in our studies. However, the presence of a marked systemic response to monosodium urate crystals has not been previously described. The pattern of the response, with the cellular response paralleling the evolution of the lesion and the acute phase response lagging behind the development of the lesion, is of particular interest. However, also notable is the marked variation between individuals in the magnitude of the SAA response.

The measurement of the acute phase protein concentrations at specific times does not allow an assessment of the flow of these proteins from the site of synthesis to the target tissues. Levels of SAA proteins thus reflect alterations of synthesis and appearance. A lag in the rise of SAA protein is, however, similar to that of CRP after surgery. ${ }^{13-15}$ With the uncertain role of these proteins in inflammation the time course of their appearance may reflect some aspect of function. Intradermal urate may allow their role in crystal induced inflammation to be explored further.

The mild transient nature of the local lesion means that it should also be acceptable for wider use in studying the acute phase response in different disease states. Although this model cannot explore the hypothesis that in diseases such as systemic lupus erythematosus the acute phase response may be blunted in flares of disease activity, it would be appropriate to explore the possibility that the systemic response to exogenous stimuli may vary between different disease states. If this can be shown, it would be more probable that abnormalities in a response to the disease process may also occur, and that these may be significant in the disease pathogenesis.

\section{References}

1 Sipe J D, Vogel S N, Sztein M B, Skinner M, Cohen A S. The role of interleukin $I$ in acute phase serum amyloid $A$ (SAA) and serum amylöd P (SAP) biosynthesis. Ann NY Acad Sci 1982; 389: $137-50$.

2 McAdam K P W J, Li J, Knowles J, et al. The biology of SAA: identification of the inducer, in vitro synthesis, and heterogeneity demonstrated by monoclonal antibodies. Ann $N Y$ Acad Sci 1982; 389: 126-36.

3 Honig S, Gorevic P, Weissmann G. C-reactive protein in systemic lupus erythematosus. Arthritis Rheum 1977; 20: 1065-70.

4 Whicher J T, Bell A M, Martin M F R, Marshall L M, Dieppe $P$ A. Prostaglandins cause an increase in serum acute phase proteins in man, which is diminished in systemic sclerosis. Clin Sci 1984; 66: 165-71.

5 McAdam K P W J, Elin R J, Sipe J J, Wolfe S M. Changes in serum amyloid $\mathrm{A}$ and $\mathrm{C}$-reactive protein after etiocholanolone induced inflammation. J Clin Invest 1978; 61: 390-4.

6 McCarty D J. Studies on the nature of gouty tophi by Max Freudweiler 1899. Ann Intern Med 1964; 60: 486-505.

7 Seegmiller J E, Howell D R, Malawista S E. The inflammatory reaction to sodium urate. JAMA 1962; 180: 469-77.

8 Faires J S, McCarty D J Jr. Acute arthritis in man and dog after intra synovial injection of sodium urate crystals. Lancet 1962; ii: 682.

9 Buchanan W W, Klinenberg J R, Secgmiller J E. The inflammatory response to injected microcrystalline monosodium urate in normal, hyperuricaemic, gouty and uremic subjects. Arthritis Rheum 1965: 8: 361 .

10 Chambers R E, Whicher J T. Quantitative radical immunodiffusion assay for SAA. J Immunol Methods 1983: 59: 95-103. 
536 Hutton, Collins, Chambers, Whicher, Dieppe

11 Ambanelli V, Ferracioli F, Mangarelli P, Varona G L. The effects of nonsteroidal anti-inflammatory drugs on monosodium urate skin test and on other in vivo skin tests (SK/SD, PHA). Agents Actions 1980; 7 (suppl): 306-9.

12 Dieppe P A, Doherty M, Papadimitriou G M. Inflammatory responses to intradermal crystals in healthy volunteers and patients with rheumatic diseases. Rheumatol Int 1982; 2: 55-8.

13 Fischer G L, Gill C, Forrester M G, Nakamura R. Quantitation

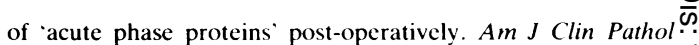
1976; 66: 840-6.

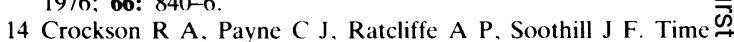
sequence of acute phase reactive proteins following surgicalo trauma. Clin Chim Acta 1966; 14: 139-46.

15 Colley C M. Fleck A. Goode A W. Muller B R. Myers M A. Early time course of the acute phase protein response in man. $J \vec{\nabla}$ Clin Pathol 1983; 36: 203-7. 